\title{
Vasculitis: do we know more to classify better?
}

\author{
Ezgi Deniz Batu $\cdot$ Seza Ozen
}

Received: 11 August 2014 /Revised: 10 November 2014 / Accepted: 11 November 2014 /Published online: 6 December 2014

(C) IPNA 2014

\begin{abstract}
The systemic vasculitides are a heterogeneous group of disorders characterized by the inflammation of blood vessels. The development and implementation of advanced diagnostic tests and genetic studies have resulted in substantial improvement in our understanding of vasculitis pathogenesis, resulting in the revision of the nomenclature and classification for vasculitis. Multicenter, collaborative studies are currently underway to develop improved diagnostic criteria. In this review, the major nomenclature and classification systems for vasculitides are summarized, with special emphasis on those emerging from the recent 2012 Chapel Hill Consensus Conference (CHCC).
\end{abstract}

Keywords Systemic vasculitis · Classification criteria . Nomenclature · ANCA-associated vasculitis · Chapel Hill Consensus Conference

\section{Introduction}

The vasculitides are a heterogeneous group of uncommon systemic disorders characterized by the inflammation of blood vessels leading to end organ injury [1]. The estimated incidence for overall childhood vasculitis is approximately 50 cases per 100,000 children per year [2]. While many vasculitides affect both children and adults, some are specific to a certain age group. Immunoglobulin A vasculitis (IgAV) [formerly Henoch-Schönlein purpura (HSP)] and Kawasaki disease (KD) are much more common in childhood, while giant cell arteritis (GCA) and cryoglobulinemic vasculitis almost never occur during childhood [3].

E. D. Batu $\cdot$ S. Ozen $(\bowtie)$

Division of Paediatric Rheumatology, Department of Paediatrics, Hacettepe University Faculty of Medicine, Ankara 06100, Turkey e-mail: sezaozen@hacettepe.edu.tr

\section{Nomenclature system, classification criteria and diagnostic criteria}

A nomenclature system includes names and definitions and provides a framework for developing classification and diagnostic criteria [4]. The products of the Chapel Hill Consensus Conference (CHCC) are nomenclature systems [5, 6].

Classification criteria are used for defining more homogeneous patient groups to facilitate research, but not for diagnosing or differentiating vasculitis from mimicking conditions [7]. The American College of Rheumatology (ACR) and Ankara Consensus Conference (Ankara) 2008 criteria are classification criteria [8-11].

Diagnostic criteria are applied to the individual patient by a physician so that a diagnosis can be made by ruling out other common conditions that may produce similar signs and symptoms [12]. There are no diagnostic criteria available for the primary systemic vasculitides.

\section{History of vasculitis nomenclature and classification}

In 1994, the International CHCC convened and proposed a nomenclature system for the most common forms of vasculitis which provided names and definitions [5].

With the substantial advances in our understanding of vasculitis pathogenesis, in 2012, a second International CHCC was held in order to add important categories of vasculitis not included in the CHCC 1994 nomenclature system [6]. The identification off anti-neutrophil cytoplasmic antibodies (ANCA) in 1982 was a great step forward in our understanding of pathogenesis in at least one group of diseases. In addition, much has been learned about clinical presentation and treatment during the last decade.

In 1990, the ACR proposed a series of classification criteria for systemic vasculitis in adults with the goal of providing a 
standard method to identify homogeneous groups of patients for research purposes $[8,9]$. Although children and adults have many signs and symptoms of vasculitis in common, they differ in the relative frequency of vasculitis subcategories and disease courses. While the ACR 1990 classification criteria were based on the more frequent features in adults, they failed to classify many children with vasculitis $[13,14]$. Therefore, it is not completely justifiable to strictly apply the ACR 1990 classification criteria to the vasculitis seen in childhood [3]. With this background, in 2005, a preliminary classification criteria were proposed by a group of pediatric rheumatologists and nephrologists for some of the most common vasculitides in childhood, namely HSP (IgAV), KD, polyarteritis nodosa (PAN), granulomatous polyangiitis (GPA) [at that time Wegener granulomatosis (WG)] and Takayasu arteritis (TA) [15]. At the 2008 Ankara Consensus Conference, these criteria were validated, and the final form was endorsed by European League Against Rheumatism (EULAR), Paediatric Rheumatology European Society (PRES) and the Pediatric Rheumatology International Trials Organization (PRINTO) [10, 11].

Then, in 2010, EULAR established an expert panel which was given the task to perform a systematic literature review and identify deficiencies in the ACR 1990 classification criteria and CHCC 1994 nomenclature system. the members of the expert panel were provided with 17 points to be considered in the development of revised classification and diagnostic criteria [16]. Many of these points had already been incorporated in the Ankara 2008 criteria, such as the use of ANCA, magnetic resonance angiography (MRA) and computed tomography angiography (CTA) in the diagnosis [10]. This study also emphasized the need for the development of a classification tree, which was provided by CHCC 2012 [6].

There are currently no diagnostic criteria for the primary systemic vasculitides. However, in practice, both the definitions provided by $\mathrm{CHCC}$ and the classification criteria are used for diagnostic purposes. A multinational observational study, the Diagnostic and Classification Criteria for Vasculitis (DCVAS) study, was designed to develop and validate diagnostic criteria and to improve and validate classification criteria for systemic vasculitides [17].

\section{Chapel Hill Consensus Conference 2012}

Chapel Hill Consensus Conference 2012 updated the definitions of vasculitis utilizing the improved understanding of the etiopathogenesis and clinical features of vasculitis subtypes [6] (Table 1). Consequently, when appropriate knowledge of the entity was available, most of the eponyms were replaced with more descriptive names. This was particularly effective in the small-vessel vasculitides (see below).
Table 1 Classification of vasculitis ${ }^{\mathrm{a}}$

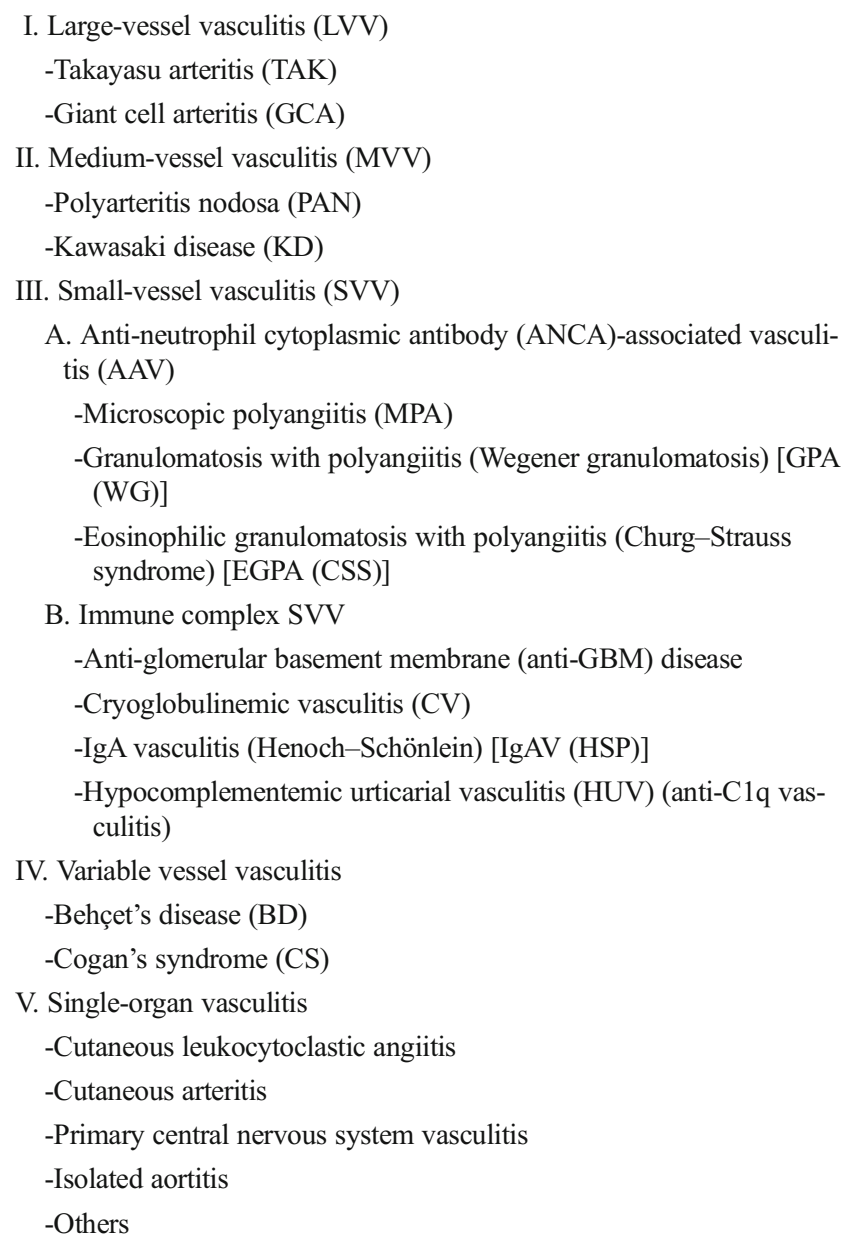

A. Anti-neutrophil cytoplasmic antibody (ANCA)-associated vasculitis (AAV)

-Microscopic polyangiitis (MPA)

-Granulomatosis with polyangiitis (Wegener granulomatosis) [GPA (WG)]

-Eosinophilic granulomatosis with polyangiitis (Churg-Strauss syndrome) [EGPA (CSS)]

B. Immune complex SVV

-Anti-glomerular basement membrane (anti-GBM) disease

-Cryoglobulinemic vasculitis (CV)

-IgA vasculitis (Henoch-Schönlein) [IgAV (HSP)]

-Hypocomplementemic urticarial vasculitis (HUV) (anti-C1q vasculitis)

IV. Variable vessel vasculitis

-Behçet's disease (BD)

-Cogan's syndrome (CS)

V. Single-organ vasculitis

-Cutaneous leukocytoclastic angiitis

-Cutaneous arteritis

-Primary central nervous system vasculitis

-Isolated aortitis

-Others

VI. Vasculitis associated with systemic disease

-Lupus vasculitis

-Rheumatoid vasculitis

-Sarcoid vasculitis

-Others

VII. Vasculitis associated with probable etiology

-Hepatitis C virus-associated cryoglobulinemic vasculitis

-Hepatitis B virus-associated vasculitis

-Syphilis-associated aortitis

-Drug-associated immune complex vasculitis

-Drug-associated ANCA-associated vasculitis

-Cancer-associated vasculitis

-Others

Classification in this table is adapted from Jennette et al. [6]

Small-vessel vasculitis

The recent progress in our understanding of the pathogenesis of small-vessel vasculitis (SVV) has enabled experts to categorize it into two main groups depending on the etiologic process: ANCA-associated vasculitis (AAV) and immune complex SVV [6]. 
The CHCC 2012 categorization emphasized the significance of ANCA in the pathogenesis of three SVV diseases. Soon after the discovery of ANCA in 1982 [18], numerous in vitro experiments and clinical observations documented that ANCA can activate neutrophils and monocytes to mediate vascular inflammation. In 2002, the first animal model of myeloperoxidase-ANCA (MPO-ANCA)-associated vasculitis was developed by Xiao et al [19]. In 2010, Primo et al described a putative animal model of AAV caused by proteinase 3-ANCA (PR3-ANCA) [20]. Work led mainly by C. Savage's group has also shed much light on the role of ANCA [21]. Studies suggest a theoretical sequence of pathogenic events: loss of tolerance, production of pathogenic levels of ANCA, ANCA binding to the antigens at the surface of neutrophils and activation of neutrophils, acute necrotizing injury with fibrinoid necrosis and leukocytoclasis by ANCA-associated neutrophils, an innate inflammatory response recruiting monocytes and $\mathrm{T}$ lymphocytes elicited by this acute injury $[21,22]$. B cells and the alternative complement pathway are also involved in the pathogenesis of SVV [21]. A number of studies have also emphasized the difficulties in differentiating microscopic polyangiitis (MPA), GPA (WG), and PAN; and the importance of ANCA in this context [23, 24].

In CHCC 2012, AAV was defined as necrotizing vasculitis with few or no immune deposits, predominantly affecting small vessels associated with MPO- or PR3-ANCA [6]. A prefix should be added to indicate ANCA reactivity as all AAV patients do not have ANCA. AAV is subdivided into MPA, GPA (WG), and eosinophilic granulomatosis with polyangiitis (EGPA) [formerly Churg-Strauss syndrome (CSS)]. Since the granulomatous and eosinophilic features of the latter two vasculitides had become evident, the eponyms WG and CSS were replaced with GPA and EGPA, respectively. GPA (WG) is necrotizing vasculitis predominantly affecting smallto medium-sized vessels, and necrotizing granulomatous inflammation usually involves the upper and lower respiratory tracts [6]. EGPA (CSS) was defined as a necrotizing vasculitis of small- to medium-sized vessels which often involves the respiratory tract together with eosinophil-rich and necrotizing granulomatous inflammation [6].

MPA was not classified as a separate entity prior to $\mathrm{CHCC}$ 2012. It is defined as a necrotizing small-vessel vasculitis with few or no immune deposits [6]. In other words, MPA is the pauci-immune SVV in the absence of evidence for GPA (WG) or EGPA (CSS) [25]. Current clinical methods have revealed that at least $80-90 \%$ of MPA (mostly MPO-ANCA) and GPA (WG) (mostly PR3-ANCA) patients and approximately $40 \%$ of EGPA (CSS) patients have ANCA [26]. These three AAV, especially GPA (WG) and MPA, are included in the same clinical studies. However, a recent genome-wide association study (GWAS) has provided evidence that GPA (WG) and MPA are indeed different diseases, while the strongest genetic associations were with the antigenic specificity of ANCA, not with the clinical syndrome [27]. GPA (WG) is associated with different HLA genes compared with MPA, and singlenucleotide polymorphisms associated with the genes encoding $\alpha 1$-antitrypsin and proteinase 3 [27].

Immune complex vasculitis is characterized by moderate to marked vessel-wall deposits of immunoglobulin and/or complement components, predominantly those affecting small vessels [6]. Anti-glomerular basement membrane disease, cryoglobulinemic vasculitis, IgAV (HSP) and hypocomplementemic urticarial vasculitis (formerly antiC1q vasculitis) are gathered under the umbrella term of immune complex vasculitis [6].

IgAV (HSP) affects small vessels with IgA1-dominant immune deposits [6]. IgA is a major class of immunoglobulin important in mucosal immunity [28], and the glycosylation of IgA1 is important in facilitating the clearance of IgA1 molecules [28]. An abnormal glycosylation of the IgA1 hinge region leads to accumulation of IgA1-dominant macromolecular complexes which activate the alternative complement pathway and result in the recruitment of inflammatory cells [29]. In CHCC 2012, the descriptive term "IgA vasculitis" replaced the eponym Henoch-Schönlein [6]. It is as yet unknown why IgAV (HSP) and IgA nephropathy behave very differently as their pathogenesis and pathology are not different: IgA nephropathy is characterized by mainly a slow and chronic course, while IgAV (HSP) has an acute and self-limiting course.

\section{Medium-vessel vasculitis}

Medium-vessel vasculitis (MVV) predominantly targets medium-sized arteries which are defined as the main visceral arteries and their branches; however, any size artery may be affected [6]. The two major variants in MVV are PAN and KD. A notable difference in the CHCC 2012 update was the addition of a negative ANCA to the definition of PAN, which is a valuable feature in distinguishing $\operatorname{PAN}$ from MPA $[6,30]$. CHCC 2012 defined PAN as a necrotizing vasculitis of medium- or small-sized arteries without glomerulonephritis or vasculitis in arterioles, venules or capillaries which is not associated with ANCA [6]. Thus, the clinical features observed in PAN are expected to be the reflection of the inflammation of the medium- or small-sized arteries. Kidney involvement will be due to the vasculitis of medium-sized arteries located before the glomerular capillaries, such as the lobar and arcuate arteries. The main renal features will therefore be hypertension, mild hematuria and proteinuria. However, it is interesting to note that in patients with familial Mediterranean fever, a number of $\operatorname{ANCA}(-)$ patients have been defined with both glomerulonephritis and proven vasculitis of medium-sized vessels, suggesting an overlap of these groups [31].

$\mathrm{KD}$ is a MVV which often involves coronary arteries and is associated with the mucocutaneous lymph node syndrome [6]. $\mathrm{KD}$ may also involve medium-sized arteries - but only rarely. 
Large-vessel vasculitis

Large-vessel vasculitis (LVV) mainly affects the aorta and its branches and includes the major categories of TA and GCA [6]. TA is mainly a disease of young adults, whereas the onset of GCA is usually in patients older than 50 years of age. GCA involves the temporal artery and is often associated with polymyalgia rheumatica [6]; it does not occur in children. The age of the patient at onset of LVV appears to be the major discriminating factor between TA and GCA in CHCC 2012.

Other categories of vasculitis

The CHCC 2012 categorizations also incorporated new categories of vasculitis, such as variable vessel vasculitis (VVV), single-organ vasculitis, vasculitis associated with systemic disease and vasculitis associated with probable etiology [6]. VVV can affect vessels of any size and type, and this category includes Behçet disease (BD) and Cogan's syndrome. Among these, BD is quite common in the countries along the Silk Road; for example, in Turkey it is more common than ANCA-associated vasculitides. It should be emphasized that BD has prominent mucocutaneous features, similar to KD.

According to the ACR criteria, hepatitis B reactant is one of the classification criteria for PAN [32]. However, in CHCC 2012, hepatitis B virus-associated vasculitis belongs to the subcategory of "vasculitis associated with probable etiology" [6]. This distinction emphasizes the difference in pathogenesis, since it is now known that infection-related PAN (or PANlike disease) is an immune complex disease, whereas classic PAN is not. This distinction also relates to treatment differences, where antiviral treatment is a part of the treatment in hepatitis B virus-related disease.

An autosomal recessive genetic disorder called "deficiency of adenosine deaminase 2 (ADA2)" (DADA2) has recently been described along with causative mutations in the CERCR1 gene [33, 34]. This disorder is characterized by systemic inflammation along with vascular features, including early-onset strokes, recurrent fevers and vasculitis. The pathology is often a necrotizing arteritis, reminiscent of PAN [33-35]. The patient who has vasculitis secondary to ADA2 deficiency should also be classified in the subcategory of "vasculitis associated with probable etiology", since this represents a vasculopathy secondary to a genetic mutation [6].

\section{Ankara 2008 criteria}

The differences between the ACR criteria [32,36-38] and the Ankara 2008 criteria [10] are summarized in Table 2.
IgAV (Henoch-Schönlein purpura)

During the revision process at the 2008 Ankara Consensus Conference, palpable purpura became a mandatory criterion, and any biopsy demonstrating "predominant" IgA deposits was accepted to be consistent with IgAV (HSP) [10]. This revision was mainly possible due to recent observations that $\operatorname{IgA}$ immune-complexes define the pathogenesis of the disease [10, 15]. Purpura was designated as the necessary criterion since it was present in all children with IgAV (HSP) in the web-based pediatric vasculitis registry of PRINTO [10]. Joint involvement, which is more common in children with IgAV (HSP) than in adults [39], and renal involvement, which determines the longterm prognosis [40], were both considered as new criteria. The age criterion was deleted since it was considered to be redundant.

Polyarteritis nodosa

The biopsy definition of ACR was considered to be very nonspecific, and thus the characteristic histopathological feature of PAN, which is the necrotizing arteritis, replaced the former. Designation of the typical histopathology or angiographic abnormalities became a mandatory criterion, and after the removal of the criteria for the signs and symptoms of vasculitis in specific organ systems, PAN classification criteria took its final form. Hepatitis B serology positivity, which was one of the ACR criteria for PAN, is unusual in childhood PAN, probably due to the vaccination protocols [41]. Thus, this criterion was deleted during revision.

Renal involvement was defined as hematuria, proteinuria or impaired renal function. The skin involvement was also provided in detail as livedo reticularis or skin nodules or skin infarcts. This was especially specified since livedo vasculitis of the previous criteria set was present in only a small proportion of patients. Again the database for PAN indeed revealed a variation of organ involvement in childhood cases. However, most of these involvements failed to reach a significant specificity and were not involved as separate items to the criteria.

Granulomatous polyangiitis (WG)

The ACR classification criteria were developed prior to ANCA being defined [37]. It is now known that approximately $90 \%$ of GPA (WG) patients are ANCA-positive (mostly PR3-ANCA) [42]. Thus, any sign of ANCA positivity was added to the group of criteria for GPA (WG) classification. The presence of subglottic, tracheal or endobronchial stenosis was also considered to be a new criterion, since it is especially common in pediatric GPA (WG) patients $[43,44]$. Furthermore, the evolving technology in imaging using Computed tomography (CT) scan results was acknowledged in the definition of pulmonary involvement. 
Table 2 ACR criteria [32, 36-38] versus Ankara 2008 criteria [10] regarding vasculitis classification

\begin{tabular}{|c|c|c|}
\hline \multirow[t]{2}{*}{ Vasculitis } & \multicolumn{2}{|l|}{ Classification criteria [reference number] } \\
\hline & ACR criteria $[32,36-38]$ & Ankara 2008 criteria [10] \\
\hline IgA vasculitis/HSP & $\begin{array}{l}\geq 2 \text { of the following: } \\
-\leq 20 \text { years of age at disease onset } \\
\text {-Palpable purpura } \\
\text {-Acute abdominal pain } \\
\text {-Biopsy showing granulocytes in the wall of small } \\
\text { arterioles/venules }\end{array}$ & $\begin{array}{l}\text { Purpura or petechia (mandatory) with lower limb predominance } \\
\text { plus } 1 \text { of } 4 \text { : } \\
\text {-Abdominal pain } \\
\text {-Histopathology (predominant IgA deposit in a biopsy) } \\
\text {-Arthritis or arthralgia } \\
\text {-Renal involvement }\end{array}$ \\
\hline Polyarteritis nodosa & $\begin{array}{l}\geq 3 \text { of the following } 10 \text { criteria: } \\
\text {-Granulocyte or mixed leukocyte infiltrate in an } \\
\text { arterial wall on biopsy } \\
\text {-Arteriographic abnormalities } \\
\text {-Livedoreticularis } \\
\text {-Myalgia } \\
\text {-Diastolic blood pressure }>90 \mathrm{mmHg} \\
\text {-Mono- or polyneuropathy } \\
\text {-Elevated blood urea nitrogen or creatinine } \\
\text {-Testicular pain/tenderness } \\
\text {-Hepatitis B reactants } \\
\text {-Weight loss }>4 \mathrm{~kg}\end{array}$ & $\begin{array}{l}\text { Histopathology or angiographic abnormalities (mandatory) plus } 1 \\
\text { of 5: } \\
\text {-Skin involvement } \\
\text {-Myalgia/muscle tenderness } \\
\text {-Hypertension } \\
\text {-Peripheral neuropathy } \\
\text {-Renal involvement }\end{array}$ \\
\hline $\begin{array}{l}\text { Granulomatous } \\
\text { polyangiitis/WG }\end{array}$ & $\begin{array}{l}\geq 2 \text { of the following: } \\
\text {-Abnormal urinary sediment (red cell casts or }>5 \\
\text { red blood cell per high power field) } \\
\text {-Abnormal findings on chest radiograph (nodules, } \\
\text { cavities, or fixed infiltrates) } \\
\text {-Oral ulcers or nasal discharge } \\
\text {-Granulomatous inflammation on biopsy }\end{array}$ & $\begin{array}{l}\text { At least } 3 \text { of } 6 \\
\text {-Histopathology (granulomatous inflammation) } \\
\text {-Upper airway involvement } \\
\text {-Laryngo-tracheo-bronchial stenosis } \\
\text {-Pulmonary involvement (chest X-ray or CT showing the } \\
\text { presence of nodules, cavities, or fixed infiltrates) } \\
\text {-ANCA positivity } \\
\text {-Renal involvement }\end{array}$ \\
\hline Takayasu arteritis & $\begin{array}{l}\geq 3 \text { of the following: } \\
\text {-Arteriographic evidence of narrowing or occlusion } \\
\text { of the entire aorta, its primary branches, or large } \\
\text { arteries in the proximal, upper or lower extremities } \\
\text {-Decreased brachial artery pulse } \\
\text {-Claudication of an extremity } \\
\text {->10 mmHg difference in systolic blood pressure } \\
\text { between arms } \\
\text {-A bruit over subclavian arteries or the aorta } \\
\text {-Age at disease onset } \leq 40 \text { years }\end{array}$ & $\begin{array}{l}\text { Angiography (conventional, CT or MRI) of the aorta or its major } \\
\text { branches and pulmonary arteries showing aneurysm/dilatation, } \\
\text { narrowing, occlusion or thickened arterial wall (mandatory) } \\
\text { plus } 1 \text { of } 5 \text { : } \\
\text {-Pulse deficit or claudication } \\
\text {-Four limbs blood pressure discrepancy }>10 \mathrm{mmHg} \\
\text {-Bruits } \\
\text {-Hypertension ( }>95 \text { percentile for height) } \\
\text {-Elevated acute phase reactants }\end{array}$ \\
\hline
\end{tabular}

ACR, American College of Rheumatology; CT, computed tomography; MRI magnetic resonance imaging

${ }^{\mathrm{a}}$ For purpura with atypical distribution, a demonstration of an immunoglobulin A deposit in a biopsy is required

\section{Takayasu arteritis}

Since the development of the ACR criteria, radiological techniques have advanced significantly. MRA and CTA have similar diagnostic performance for TA and are less invasive when compared to conventional angiography $[45,46]$. Thus, during the revision process, the angiographic abnormalities became mandatory criteria and modified with the imaging modalities, such as MRA, CTA and conventional angiography. The age criterion was deleted, and hypertension was included since almost all of the childhood cases had this clinical feature [10]. Elevated acute phase reactants were added as a new criterion, although not all patients have elevated acute phase response. This criterion was added to aid in the differential diagnosis with fibromuscular disease in children. With all of these modifications, the criteria had a sensitivity of $100 \%$ and a specificity of $99 \%$ in children.

\section{Conclusion}

Advances in diagnostic technology and improvement in our understanding of etiopathogenesis, mainly through GWAS and other genetic studies, have provided physicians with more detailed data on vasculitis in recent years. The definitions and classification criteria have also evolved with these advances. However, there are still no diagnostic criteria for the primary 
systemic vasculitides, necessitating a reliance on disease definitions and physician experience for a differential diagnosis. Collaborative multicenter studies such as DCVAS are needed to develop diagnostic criteria while improving the existing classification criteria. However, with the availability of classification criteria, the pediatric agenda should focus on multicenter studies to define better management and treatment programs for patients with these rare diseases.

\section{Key summary points}

1. Classification criteria are used for defining more homogeneous patients groups for research purposes and would facilitate diagnosis by ruling out mimicking conditions.

2. The updated CHCC 2012 definitions provide a classification tree which forms a basis for future classification and diagnostic criteria for vasculitis in both children and adults.

3. Vasculitis in children differs from that in adults in specific aspects, particularly in the frequency of vasculitis subcategories, the predominant presenting features and disease course.

\section{Questions (answers are provided following the reference list)}

1. Which of the following is false for the CHCC 2012 classification and diagnostic criteria?

a) They have redefined the diseases using new data for the respective pathogenesis.

b) They cannot be relied upon for the diagnosis of an individual patient.

c) They provide strict criteria to diagnose patients.

d) They are a nomenclature system providing definitions for the diseases.

e) They are not a revision of the ACR 1990 criteria.

2. For PAN, which of the following is correct?

a) Glomerulonephritis is the usual renal manifestation.

b) Hepatitis B serology is usually positive in children with PAN.

c) ANCA positivity is an important feature of PAN distinguishing it from MPA.

d) Designating the typical histopathology or angiographic abnormalities is a mandatory criterion for PAN based on Ankara 2008 criteria.

e) PAN predominantly affects the arterioles, venules and capillaries.

3. Which of the following is false regarding ANCA?
a) ANCA plays a role in the pathogenesis of some MVV.
b) ANCA can activate the neutrophils and monocytes to mediate an inflammatory process.
c) There are animal models for AAV caused by MPO- and PR3-ANCA.
d) GPA (WG), MPA and EGPA (CSS) are major cate- gories of AAV.
e) Approximately $40 \%$ of EGPA (CSS) patients have ANCA.

4. A 10-year-old boy has repeated sinus infections, nasal septum perforation, nodular masses in the lungs, red blood cell casts in urine and PR3-ANCA positivity. Which one is the most likely diagnosis?
a) IgAV (HSP)
b) PAN
c) MPA
d) EGPA (CSS)
e) GPA (WG)

5. According to the Ankara 2008 criteria, elevated acute phase reactants is a criterion for classifying:
a) $\operatorname{IgAV}(\mathrm{HSP})$
b) $\mathrm{TA}$
c) $\mathrm{KD}$
d) GPA (WG)
e) PAN

\section{References}

1. Brogan PA, Dillon MJ (2000) Vasculitis from the pediatric perspective. Curr Rheumatol Rep 2:411-416

2. Gardner-Medwin JM, Dolezalova P, Cummins C, Southwood TR (2002) Incidence of Henoch-Schonlein purpura, Kawasaki disease, and rare vasculitides in children of different ethnic origins. Lancet 360:1197-1202

3. Ozen S (2005) Problems in classifying vasculitis in children. Pediatr Nephrol 20:1214-1218

4. Jennette JC (2013) Overview of the 2012 revised International Chapel Hill Consensus Conference nomenclature of vasculitides. Clin Exp Nephrol 17:603-606

5. Jennette JC, Falk RJ, Andrassy K, Bacon PA, Churg J, Gross WL, Hagen EC, Hoffman GS, Hunder GG, Kallenberg CG (1994) Nomenclature of systemic vasculitides. Proposal of an international consensus conference. Arthritis Rheum 37:187-192

6. Jennette JC, Falk RJ, Bacon PA, Basu N, Cid MC, Ferrario F, FloresSuarez LF, Gross WL, Guillevin L, Hagen EC, Hoffman GS, Jayne DR, Kallenberg CG, Lamprecht P, Langford CA, Luqmani RA, Mahr AD, Matteson EL, Merkel PA, Ozen S, Pusey CD, Rasmussen N, Rees AJ, Scott DG, Specks U, Stone JH, Takahashi K, Watts RA (2013) 2012 Revised International Chapel Hill Consensus Conference Nomenclature of Vasculitides. Arthritis Rheum 65:1-11

7. Jennette JC, Falk RJ (2000) Do vasculitis categorization systems really matter? Curr Rheumatol Rep 2:430-438 
8. Bloch DA, Michel BA, Hunder GG, McShane DJ, Arend WP, Calabrese LH, Edworthy SM, Fauci AS, Fries JF, Leavitt RY (1990) The American College of Rheumatology 1990 criteria for the classification of vasculitis. Patients and methods. Arthritis Rheum 33:1068-1073

9. Hunder GG, Arend WP, Bloch DA, Calabrese LH, Fauci AS, Fries JF, Leavitt RY, Lie JT, Lightfoot RW Jr, Masi AT (1990) The American College of Rheumatology 1990 criteria for the classification of vasculitis. Introduction. Arthritis Rheum 33:1065-1067

10. Ozen S, Pistorio A, Iusan SM, Bakkaloglu A, Herlin T, Brik R, Buoncompagni A, Lazar C, Bilge I, Uziel Y, Rigante D, Cantarini L, Hilario MO, Silva CA, Alegria M, Norambuena X, Belot A, Berkun Y, Estrella AI, Olivieri AN, Alpigiani MG, Rumba I, Sztajnbok F, Tambic-Bukovac L, Breda L, Al-Mayouf S, Mihaylova D, Chasnyk V, Sengler C, Klein-Gitelman M, Djeddi D, Nuno L, Pruunsild C, Brunner J, Kondi A, Pagava K, Pederzoli S, Martini A, Ruperto N, Paediatric Rheumatology International Trials O (2010) EULAR/PRINTO/PRES criteria for Henoch-Schonlein purpura, childhood polyarteritis nodosa, childhood Wegener granulomatosis and childhood Takayasu arteritis: Ankara 2008. Part II: Final classification criteria. Ann Rheum Dis 69:798-806

11. Ruperto N, Ozen S, Pistorio A, Dolezalova P, Brogan P, Cabral DA, Cuttica R, Khubchandani R, Lovell DJ, O’Neil KM, Quartier P, Ravelli A, Iusan SM, Filocamo G, Magalhaes CS, Unsal E, Oliveira S, Bracaglia C, Bagga A, Stanevicha V, Manzoni SM, Pratsidou P, Lepore L, Espada G, Kone-Paut I, Zulian F, Barone P, Bircan Z, Maldonado Mdel R, Russo R, Vilca I, Tullus K, Cimaz R, Horneff G, Anton J, Garay S, Nielsen S, Barbano G, Martini A, Paediatric Rheumatology International Trials O (2010) EULAR/ PRINTO/PRES criteria for Henoch-Schonlein purpura, childhood polyarteritis nodosa, childhood Wegener granulomatosis and childhood Takayasu arteritis: Ankara 2008. Part I: overall methodology and clinical characterisation. Ann Rheum Dis 69:790-797

12. Hunder GG (1998) The use and misuse of classification and diagnostic criteria for complex diseases. Ann Intern Med 129:417-418

13. Bowyer S, Roettcher P (1996) Pediatric rheumatology clinic populations in the United States: results of a 3 year survey. Pediatric Rheumatology Database Research Group. J Rheumatol 23:19681974

14. Malleson PN, Fung MY, Rosenberg AM (1996) The incidence of pediatric rheumatic diseases: results from the Canadian Pediatric Rheumatology Association Disease Registry. J Rheumatol 23: 1981-1987

15. Ozen S, Ruperto N, Dillon MJ, Bagga A, Barron K, Davin JC, Kawasaki T, Lindsley C, Petty RE, Prieur AM, Ravelli A, Woo P (2006) EULAR/PReS endorsed consensus criteria for the classification of childhood vasculitides. Ann Rheum Dis 65:936-941

16. Basu N, Watts R, Bajema I, Baslund B, Bley T, Boers M, Brogan P, Calabrese L, Cid MC, Cohen-Tervaert JW, Flores-Suarez LF, Fujimoto S, de Groot K, Guillevin L, Hatemi G, Hauser T, Jayne D, Jennette C, Kallenberg CG, Kobayashi S, Little MA, Mahr A, McLaren J, Merkel PA, Ozen S, Puechal X, Rasmussen N, Salama A, Salvarani C, Savage C, Scott DG, Segelmark M, Specks U, Sunderkoetter C, Suzuki K, Tesar V, Wiik A, Yazici H, Luqmani R (2010) EULAR points to consider in the development of classification and diagnostic criteria in systemic vasculitis. Ann Rheum Dis 69: 1744-1750

17. Craven A, Robson J, Ponte C, Grayson PC, Suppiah R, Judge A, Watts R, Merkel PA, Luqmani RA (2013) ACR/EULAR-endorsed study to develop Diagnostic and Classification Criteria for Vasculitis (DCVAS). Clin Exp Nephrol 17:619-621

18. van der Woude FJ, Rasmussen N, Lobatto S, Wiik A, Permin H, van Es LA, van der Giessen M, van der Hem GK, The TH (1985) Autoantibodies against neutrophils and monocytes: tool for diagnosis and marker of disease activity in Wegener's granulomatosis. Lancet $1: 425-429$
19. Xiao H, Heeringa P, Hu P, Liu Z, Zhao M, Aratani Y, Maeda N, Falk RJ, Jennette JC (2002) Antineutrophil cytoplasmic autoantibodies specific for myeloperoxidase cause glomerulonephritis and vasculitis in mice. J Clin Invest 110:955-963

20. Primo VC, Marusic S, Franklin CC, Goldmann WH, Achaval CG, Smith RN, Arnaout MA, Nikolic B (2010) Anti-PR3 immune responses induce segmental and necrotizing glomerulonephritis. Clin Exp Immunol 159:327-337

21. Savage CO (2011) Pathogenesis of anti-neutrophil cytoplasmic autoantibody (ANCA)-associated vasculitis. Clin Exp Immunol 164[Suppl 1]:23-26

22. Jennette JC, Falk RJ, Hu P, Xiao H (2013) Pathogenesis of antineutrophil cytoplasmic autoantibody-associated small-vessel vasculitis. Annu Rev Pathol 8:139-160

23. Uribe AG, Huber AM, Kim S, O’Neil KM, Wahezi DM, Abramson L, Baszis K, Benseler SM, Bowyer SL, Campillo S, Chira P, Hersh AO, Higgins GC, Eberhard A, Ede K, Imundo LF, Jung L, Kingsbury DJ, Klein-Gitelman M, Lawson EF, Li SC, Lovell DJ, Mason T, McCurdy D, Muscal E, Nassi L, Rabinovich E, Reiff A, Rosenkranz M, Schikler KN, Singer NG, Spalding S, Stevens AM, Cabral DA, Network ARfCwVe-e (2012) Increased sensitivity of the European medicines agency algorithm for classification of childhood granulomatosis with polyangiitis. J Rheumatol 39:1687-1697

24. Watts R, Lane S, Hanslik T, Hauser T, Hellmich B, Koldingsnes W, Mahr A, Segelmark M, Cohen-Tervaert JW, Scott D (2007) Development and validation of a consensus methodology for the classification of the ANCA-associated vasculitides and polyarteritis nodosa for epidemiological studies. Ann Rheum Dis 66:222-227

25. Jennette JC, Falk RJ (1997) Small-vessel vasculitis. N Engl J Med 337:1512-1523

26. Jennette JCFR (2007) ANCA vasculitis: microscopic polyangiitis, Wegener's granulomatosis and Churg-Strauss syndrome. Pathol Case Rev 12:200-221

27. Lyons PA, Rayner TF, Trivedi S, Holle JU, Watts RA, Jayne DR, Baslund B, Brenchley P, Bruchfeld A, Chaudhry AN, Cohen Tervaert JW, Deloukas P, Feighery C, Gross WL, Guillevin L, Gunnarsson I, Harper L, Hruskova Z, Little MA, Martorana D, Neumann T, Ohlsson S, Padmanabhan S, Pusey CD, Salama AD, Sanders JS, Savage CO, Segelmark M, Stegeman CA, Tesar V, Vaglio A, Wieczorek S, Wilde B, Zwerina J, Rees AJ, Clayton DG, Smith KG (2012) Genetically distinct subsets within ANCA-associated vasculitis. N Engl J Med 367:214-223

28. Kerr MA (1990) The structure and function of human IgA. Biochem J 271:285-296

29. Kiryluk K, Moldoveanu Z, Sanders JT, Eison TM, Suzuki H, Julian BA, Novak J, Gharavi AG, Wyatt RJ (2011) Aberrant glycosylation of IgA1 is inherited in both pediatric IgA nephropathy and HenochSchonlein purpura nephritis. Kidney Int 80:79-87

30. Guillevin L, Lhote F, Amouroux J, Gherardi R, Callard P, Casassus P (1996) Antineutrophil cytoplasmic antibodies, abnormal angiograms and pathological findings in polyarteritis nodosa and Churg-Strauss syndrome: indications for the classification of vasculitides of the polyarteritis Nodosa Group. Br J Rheumatol 35:958-964

31. Ozen S, Ben-Chetrit E, Bakkaloglu A, Gur H, Tinaztepe K, Calguneri M, Turgan C, Turkmen A, Akpolat I, Danaci M, Besbas N, Akpolat T (2001) Polyarteritis nodosa in patients with Familial Mediterranean Fever (FMF): a concomitant disease or a feature of FMF? Semin Arthritis Rheum 30:281-287

32. Lightfoot RW Jr, Michel BA, Bloch DA, Hunder GG, Zvaifler NJ, McShane DJ, Arend WP, Calabrese LH, Leavitt RY, Lie JT (1990) The American College of Rheumatology 1990 criteria for the classification of polyarteritis nodosa. Arthritis Rheum 33:1088-1093

33. Zhou Q, Yang D, Ombrello AK, Zavialov AV, Toro C, Zavialov AV, Stone DL, Chae JJ, Rosenzweig SD, Bishop K, Barron KS, Kuehn HS, Hoffmann P, Negro A, Tsai WL, Cowen EW, Pei W, Milner JD, Silvin C, Heller T, Chin DT, Patronas NJ, Barber JS, Lee CC, Wood 
GM, Ling A, Kelly SJ, Kleiner DE, Mullikin JC, Ganson NJ, Kong HH, Hambleton S, Candotti F, Quezado MM, Calvo KR, Alao H, Barham BK, Jones A, Meschia JF, Worrall BB, Kasner SE, Rich SS, Goldbach-Mansky R, Abinun M, Chalom E, Gotte AC, Punaro M, Pascual V, Verbsky JW, Torgerson TR, Singer NG, Gershon TR, Ozen S, Karadag O, Fleisher TA, Remmers EF, Burgess SM, Moir SL, Gadina M, Sood R, Hershfield MS, Boehm M, Kastner DL, Aksentijevich I (2014) Early-onset stroke and vasculopathy associated with mutations in ADA2. N Engl J Med 370:911-920

34. Navon Elkan P, Pierce SB, Segel R, Walsh T, Barash J, Padeh S, Zlotogorski A, Berkun Y, Press JJ, Mukamel M, Voth I, Hashkes PJ, Harel L, Hoffer V, Ling E, Yalcinkaya F, Kasapcopur O, Lee MK, Klevit RE, Renbaum P, Weinberg-Shukron A, Sener EF, Schormair B, Zeligson S, Marek-Yagel D, Strom TM, Shohat M, Singer A, Rubinow A, Pras E, Winkelmann J, Tekin M, Anikster Y, King MC, Levy-Lahad E (2014) Mutant adenosine deaminase 2 in a polyarteritis nodosa vasculopathy. N Engl J Med 370:921-931

35. Garg N, Kasapcopur O, Foster J 2nd, Barut K, Tekin A, Kizilkilic O, Tekin M (2014) Novel adenosine deaminase 2 mutations in a child with a fatal vasculopathy. Eur J Pediatr 173:827-830

36. Arend WP, Michel BA, Bloch DA, Hunder GG, Calabrese LH, Edworthy SM, Fauci AS, Leavitt RY, Lie JT, Lightfoot RW Jr (1990) The American College of Rheumatology 1990 criteria for the classification of Takayasu arteritis. Arthritis Rheum 33:1129-1134

37. Leavitt RY, Fauci AS, Bloch DA, Michel BA, Hunder GG, Arend WP, Calabrese LH, Fries JF, Lie JT, Lightfoot RW Jr (1990) The American College of Rheumatology 1990 criteria for the classification of Wegener's granulomatosis. Arthritis Rheum 33:1101-1107

38. Mills JA, Michel BA, Bloch DA, Calabrese LH, Hunder GG, Arend WP, Edworthy SM, Fauci AS, Leavitt RY, Lie JT (1990) The American College of Rheumatology 1990 criteria for the classification of Henoch-Schonlein purpura. Arthritis Rheum 33:1114-1121

39. Kang Y, Park JS, Ha YJ, Kang MI, Park HJ, Lee SW, Lee SK, Park YB (2014) Differences in clinical manifestations and outcomes between adult and child patients with Henoch-Schonlein purpura. J Korean Med Sci 29:198-203

40. Jauhola O, Ronkainen J, Koskimies O, Ala-Houhala M, Arikoski P, Holtta T, Jahnukainen T, Rajantie J, Ormala T, Turtinen J, Nuutinen M (2010) Renal manifestations of Henoch-Schonlein purpura in a 6month prospective study of 223 children. Arch Dis Child 95:877-882

41. Ozen S (2004) Juvenile polyarteritis: is it a different disease? J Rheumatol 31:831-832
42. Vanoni F, Bettinelli A, Keller F, Bianchetti MG, Simonetti GD (2010) Vasculitides associated with IgG antineutrophil cytoplasmic autoantibodies in childhood. Pediatr Nephrol 25:205-212

43. Belostotsky VM, Shah V, Dillon MJ (2002) Clinical features in 17 paediatric patients with Wegener granulomatosis. Pediatr Nephrol 17: 754-761

44. Rottem M, Fauci AS, Hallahan CW, Kerr GS, Lebovics R, Leavitt RY, Hoffman GS (1993) Wegener granulomatosis in children and adolescents: clinical presentation and outcome. J Pediatr 122:26-31

45. Yamada I, Nakagawa T, Himeno Y, Kobayashi Y, Numano F, Shibuya H (2000) Takayasu arteritis: diagnosis with breath-hold contrast-enhanced three-dimensional MR angiography. J Magn Reson Imaging 11:481-487

46. Yamada I, Nakagawa T, Himeno Y, Numano F, Shibuya H (1998) Takayasu arteritis: evaluation of the thoracic aorta with CT angiography. Radiology 209:103-109

\section{Answers}

1. c. The diagnostic criteria are used to diagnose individual patients by ruling out mimicking conditions. Nomenclature systems such as CHCC 2012 are not used for this purpose [7].

2. d. Designating the typical histopathology or angiographic abnormalities became a mandatory criterion for PAN during the revision process of vasculitis criteria at the 2008 Ankara Consensus Conference [10].

3. a. ANCA plays a role in the pathogenesis of AAV which is a category of SVV [6].

4. e. The child presents with upper respiratory system, lung and renal involvement. It is difficult to distinguish between GPA (WG) and MPA. However, PR3-ANCA positivity makes GPA (WG) the most likely diagnosis [26].

5. b. The Ankara 2008 criteria for TA are angiographic abnormalities of the aorta and its main branches and pulmonary arteries showing aneurysm/dilatation (mandatory criterion) plus one of the following five: pulse deficit or claudication, four limb blood pressure discrepancy, bruits, hypertension and elevation of acute phase reactants [10]. 